\title{
Recovery time analysis of back muscle fatigue in panelized residential modular construction factory
}

\author{
SangJun $\mathrm{Ahn}^{1 *}$, SangUk Han ${ }^{2}$ and Mohamed Al-Hussein ${ }^{3}$ \\ ${ }^{1}$ PhD Student, Department of Civil and Environmental Engineering, University of Alberta \\ ${ }^{2}$ Assistant Professor, Department of Civil and Environmental Engineering, University of Alberta \\ ${ }^{3}$ Professor, Department of Civil and Environmental Engineering, University of Alberta \\ *Corresponding author's e-mail: sangjun@ualberta.ca
}

\begin{abstract}
Construction workers in panelized construction factory settings are often exposed to physically demanding and repetitive activities during panel assembly, which requires manual processes. Consequently, these factory workers are often exposed to potential risks, namely work-related musculoskeletal disorders (WMSDs), due to muscle fatigue. Therefore, it is important to evaluate levels of fatigue and provide appropriate interventions to minimize the health risk of workers. Previous studies have shown that sufficient rest could reduce risk of WMSDs from fatigue and is considered one of most practical way to minimize risk. Rest break schedule analysis on worker's fatigue in different industries has been documented; however, to the author's knowledge, the analysis on panelized construction has not yet been studied. To address this gap, fatigue of workers is estimated using an equation, which was derived mathematically, in terms of recovery time compared with break time schedule. A case study of a panelized construction factory in Edmonton, Alberta, Canada is performed to evaluate the effectiveness of rest break schedules. The results from the case study show that workers at the panelized construction factory require more frequent and longer break time to reduce potential risk of WMSDs.
\end{abstract}

\section{KEYWORDS}

Rest allowance; back muscle fatigue; modular construction; maximum voluntary contraction

\section{INTRODUCTION}

Construction industries have been adopting a modular construction method in order to overcome issues from traditional construction processes over the past few decades. The issues such as construction period, cost, on-site safety, product quality, and waste are major problems that require high levels of human and capital resources to manage. Unlike the traditional construction method, most modular construction processes are carried out in controlled environmental settings such as a factory. Standardized and automatized module manufacturing processes significantly reduce cost, time, and waste of construction, and also increase on-site safety of workers (Kamali \& Hewage, 2016). Previous study has proven that $80 \%$ of reportable accidents (e.g., fatal injuries) from on-site construction work can be reduced if modular construction is utilized (Lawson et al., 2012). However, off-site construction methods, such as modular construction, could contain a 
greater exposure of worker-related injuries than traditional construction. In terms of safety, modular construction could reduce on-site safety issues, but at the same time, it also may increase ergonomic problems such as WMSDs from non-automatized manual work. The work usually consists of complicated, repetitive, and physically challenging activities that involve potential ergonomic risk factors (Golabchi et al., 2015).

Panelized construction is one type of modular construction that is applied in residential construction in which potential WMSD risks to workers were found through previous ergonomic study (Golabchi et al., 2015). In the panelized construction method, each section of a building (e.g., floor, wall, roof, etc.) is pre-assembled as modules in the factory, which are then transported to the construction site for erection using a crane. A study by Kim et al. (2011) took place at a panelized construction factory in the United States in order to measure ergonomic risks of workers. As a result, they found that high risk of WMSD on the back exists among workers, and $77 \%$ of the total measurement of shear force on workers' backs exceeds the limit of physical capacity (e.g., MVC) (Kim, et al., 2011).

One method to reduce potential risks of WMSDs is to take a sufficient rest breaks (El ahrache \& Imbeau, 2009). During the break, muscles that have become fatigued can recover back to their original condition. But, if fatigue accumulates without recovery then potential risk of WMSDs can be increased (Chaffin \& Park, 1973). According to the Canadian Centre for Occupational Health and Safety (CCOHS), recommended rest break time is two 15-minute breaks during midmorning and afternoon, and one 30-minute break for lunch. However, the CCOHS does not distinguish between different physical levels of work. In Alberta, the employment standard requires 30 minutes of break for workers if a shift is longer than 5 hours; on the other hand, if a shift is less than 5 hours then employee does not have to provide any rest break (Government of Alberta, 2011). Considering the level of physically demanding activities and corresponding WMSD risks in panelized construction factories as shown in previous studies (Kim et al., 2011; Golabchi et al., 2015), the recommended rest breaks may not be sufficient to protect workers from potential risk of WMSDs.

This study aims to understand the relationship between break time schedule and cumulated muscle fatigue. A mathematical model is applied to estimate muscle fatigue. Through a case study, the impact of current break time schedule on fatigue is evaluated, and alternative break times are compared in order to evaluate the effectiveness of break time schedule on potential risk of WMSD.

\section{RESEARCH BACKGROUND}

\section{Low back injuries in panelized construction}

In panelized construction, workers are exposed to WMSD risks of the back during erection of wall panels (Kim et al., 2011). The wall panel erection processes are carried out manually by two workers. The wall panels are carried from the production line and erected in designated positions on the finished floor panels. Electromyography (EMG) sensors were used in order to measure and estimate applied forces on workers' back muscles (Kim et al., 2011). Back muscles of workers are the most injury prone body part in panelized construction (Nussbaum et al., 2009). Activities at the panelized construction factory are often related to lifting, lowering, carrying, pushing, pulling, and twisting; these postures could lead to potential back injuries, especially low-back, and, if they are repeated for a long period of time, permanent damage may occur (CPWR, 2004). Other ergonomic studies on lifting have found that back muscle injury rates are correlated with weight and frequency of lifting (Chaffin \& Park, 1973; Marras, 2000). Also, 
statistics from the CPWR show that back related injuries are the most commonly found WMSDs in the construction industry in between 2003 and 2010, and account for 16\% of the total nonfatal injuries (CPWR, 2013).

\section{Recovery time}

The CCOHS provides a general description of back injury prevention methods (e.g., elimination of handling heavy manual work, reduction of stressful body postures, changing pace of work, and improvement on working environment), one of which is to take a rest breaks (CCOHS, 2016). According to previous studies on breaks during physical work, one practical way to reduce risk of WMSDs is to take sufficient rest breaks during work (El ahrache \& Imbeau, 2009). Also, proper rest break design at a physically demanding workplace could be used as a tool to reduce muscle fatigue and increase safety of workers (Arlinghaus et al., 2012). Without proper breaks, physical activity may lead to the fatigue failure point, at which the muscles are exhausted and chronic damage to muscles may occur (McGill, 1997). Long-term repetition of continuous exhaustion of muscles without sufficient breaks would cause WMSDs (Kumar, 2001). Sufficient rest periods or recovery time can be estimated using mathematical models (El ahrache \& Imbeau, 2009). Different mathematical models are listed in Table 1 and inputs for the models generally consist of maximum voluntary contraction (MVC) or maximum holding time (MHT). These values are based on workers' physical ability of muscles that endure maximum force.

Table 1. Comparison between different recovery models (El ahrache \& Imbeau, 2009)

\begin{tabular}{lcc}
\hline Model & \multicolumn{1}{c}{ Equation } & Description \\
\hline $\begin{array}{l}\text { Rohmert } \\
\text { (1973) } \\
\text { Milner } \\
(1985)\end{array}$ & $R A=18 \times(f M H T)^{1.4} \times(f M V C-0.15)^{0.5} \times 100$ & $\begin{array}{c}\text { No fatigue if \%MVC } \\
\text { less than 15\% } \\
\text { Jobs that affect back } \\
\text { and lower limbs the } \\
\text { most }\end{array}$ \\
$\begin{array}{l}\text { Rose } \\
\text { et al. (1992) } \\
\text { Byström and } \\
\text { Frasson-Hall } \\
(1994)\end{array}$ & $\begin{array}{c}1 \\
\times 100\end{array}$ & $\begin{array}{c}\text { Not specific to any } \\
\text { particular body parts } \\
\text { No fatigue if \%MVC } \\
\text { less than } 15 \%\end{array}$ \\
\hline
\end{tabular}

$\mathrm{fMVC}=\% \mathrm{MVC} / 100 ; \mathrm{fMHT}=$ holding time $/ \mathrm{MHT}$

The recovery time is the amount of time required for muscles to return to $100 \%$ of maximum voluntary contraction (MVC), and the MVC is the largest muscular efforts that can be performed during a single activity (Parker, 2009). For example, MVC of back muscles for average person is $50 \mathrm{~kg}$, and recovery time is 10 minutes; in other words, in order to safely life $50 \mathrm{~kg}$ by using the same back muscles, a person should wait at least 10 minutes to lift the object without damaging the back muscles. The maximum holding time (MHT) is how long workers can lift objects without releasing. The output of the models is recovery time in minutes.

\section{METHODS}

In order to evaluate potential risks of WMSDs, current practice rest breaks at the modular construction factory are compared against the minimum required rest break time for workers as part of a case study at a panelized construction factory in Edmonton. The minimum break time is 
estimated based on recovery time models. For the estimation of recovery time, models require two different inputs such as weight of object, MVC of worker, and contraction time (CT). The contraction time is when worker uses back muscles. Once the data collection is completed, recovery time for each lifting and lowering process is estimated using the Rohmert model in Table 1. For analysis of the recover times, the times are accumulated over working hours (e.g., 7:00 AM to 5:00 PM) in order to capture total exposure from fatigue during work. This approach has been applied in previous ergonomic analysis and has shown additional risk of WMSDs which provides an overall understanding of the risk (Dode et al., 2016).

\section{Data Collection}

In order to estimate recovery time, the mathematical models are applied with three different inputs as follows: weight of each panel, MVC of worker, and CT. First, the weight of the panel is estimated using the weight per length ratio from the manufacture. Next, MVC of worker is acquired from a previous study on back muscle strengths. The study provides statistical data of back muscle MVC of 50 different male adults between 15 and 55 years of age (Poulsen \& Jorgensen, 1971). Physical dimensions such as height and weight of two workers at the factory are consistent with the dimensions of sample male adults in the study. In this study, lifting and lowering of panel processes are considered as the contraction time, and the times are recorded in minutes.

\section{Estimation of recovery time}

Four different recovery time estimation models were introduced in Table 1 in the previous section. In this study, the Rohmert model is selected for the estimation of recovery time due to well documented MHT time studies that have previously applied the model (Frey-Law et al., 2012), and it has been widely used to estimate work rest cycles by ergonomists (Loof, 2012). Equation (1) (Rohmert, 1960) is applied to calculate the \% $\mathrm{MCV}$ of panel installation activity. Each time a worker lifts and lowers a panel, the recovery time for the activity is calculated based on the weight of the panel and MVC of the worker.

$$
\% M V C=100 \% \times \text { weight of panel } \div \text { MVC of worker }
$$

Then, the MHT is calculated using Equation (2) (Rohmert, 1960). The result of the equation is in minutes that represent muscle endurance.

$$
M H T=-1.5+\frac{2.1}{\% M V C}-\frac{0.6}{\% M V C^{2}}+\frac{0.1}{\% M V C^{3}}
$$

Lastly, recovery time is calculated based on MHT and \%MVC using Equation (3) (Rohmert, 1960). Similar to MHT, the unit of time is in minutes. The recovery time represents the minimum time required to recover the physical capacity of muscle to its original status.

$$
\text { Recovery Time }=18 \times(C T / M H T)^{1.4} \times(\% M V C-0.15)^{0.5} \times C T
$$

\section{Analysis of break time}

The break time analysis examines the effectiveness of rest break schedules that reduce potential risk of WMSDs of the back. In order to determine the effectiveness of a rest break, an area under 
a plot is compared with different rest break schedules. The plot is generated with accumulated recovery time against working hours (7:00 AM to 5:00 PM). Each time workers perform lifting or lowering the recovery time is estimated using the model and added to previously accumulated time. However, if workers do not utilize back muscles, such as for walking without any object or talking, then the duration of activity is deducted from the previously accumulated data. Once the plot is completed, areas under the accumulated line are estimated using the trapezoid rule that has been applied to approximate areas under a curve in the past. The areas under a curve represent estimated total fatigue on workers.

The minimum required recovery time is also estimated to quantify potential risk of WMSD. The minimum time represents a point where workers may apply a larger physical force than capacity of muscle. In other words, it is the point where \%MVC of the worker is greater than $100 \%$. For example, if a weight of panel is greater than MVC of worker then $\% \mathrm{MVC}$ can be greater than $100 \%$. The minimum time is calculated based on Equations (1), (2), and (3) above. Equations (1) and (2) are plugged into Equation (3) so that the recovery time can be expressed as CT and $\% \mathrm{MVC}$. Then $\% \mathrm{MVC}$ is set to $100 \%$ in order to find the amount of time that has a potential risk of WMSD, and the average CT from the entire panel of data will be used.

\section{CASE STUDY: RESULTS AND DISCUSSION}

A panelized construction factory in Edmonton, Alberta is selected for the case study. Actual working processes at the factory are monitored for collection of input data. Specifically, one of the floor module assembly tables is monitored between the working hours of 7:00 AM and 5:00 PM with two 15-minute coffee breaks and one 30-minute lunch break during the work shift. Depending on the situation, one or two workers work on the table to lay out wood panels before the CNC machine performs the tasks of gluing, nailing, or cutting. Once the pre-cut wood panels are delivered to the table using the racks, workers begin to lay them out according to given CAD drawings. During the case study, a total of 121 wood panels are installed by the workers. The weight of one panel is approximately $2.5 \mathrm{lbs} / \mathrm{LF}$. For example, if a worker lifts 10 feet of panel, the weight would be close to $25 \mathrm{lbs}$. Each recovery time is estimated according to the back muscle utilized in activities such as lifting and lowering, and the times are accumulated with previous times as the number of working hours increases. The total recovery time plot is generated as shown in Figure 3 below.

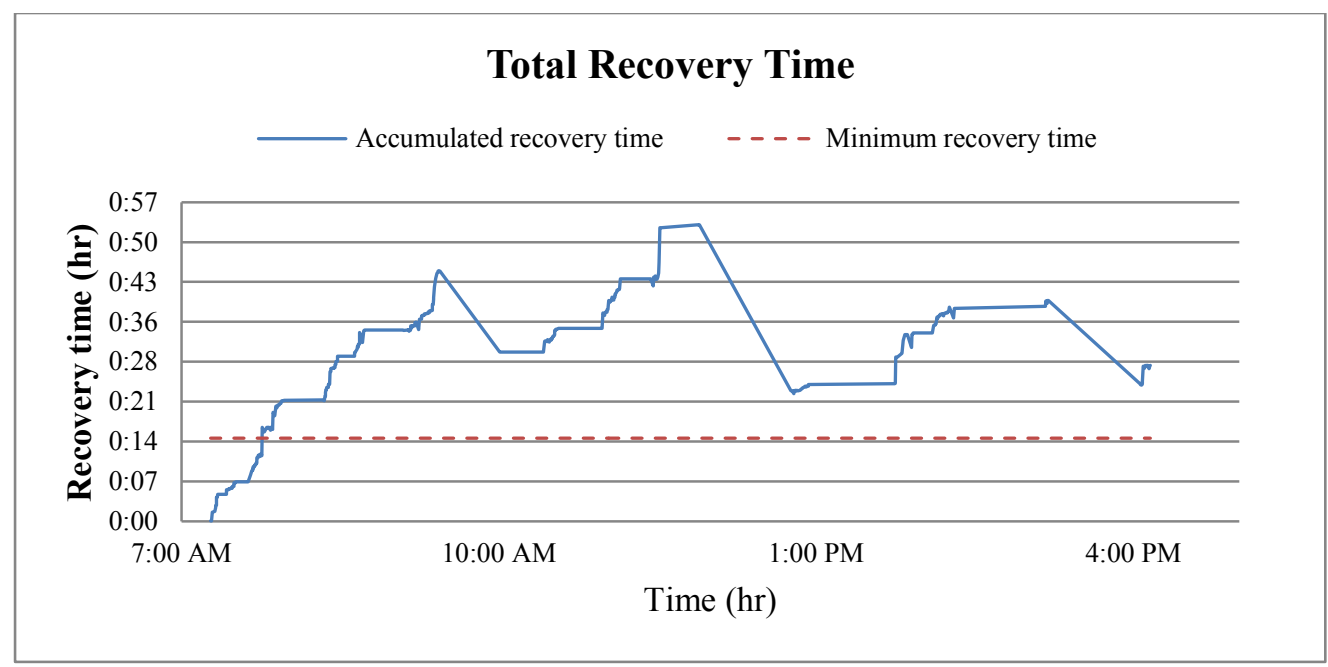

Figure 3. Accumulated recovery times 
The minimum required recovery time is also estimated using the average contraction time (e.g., 0.25 minutes) and the maximum weight of a panel (e.g., $22.3 \mathrm{~kg}$ ), and is represented in Figure 3 as a dashed line.

Three different break times are applied to measure their total fatigue and effectiveness by comparing the area between the two lines in Figure 3. The first break schedule's current practice is that workers have two 15-minute breaks, one in the morning (e.g., 9:30 AM) and afternoon (e.g., 2:30 PM), and one 30-minute lunch break at 12:00 PM, totalling 60 minutes of rest for workers. The two 15-minute breaks are placed in the middle of the morning working hours (between 7:00 AM and 12:00 PM) and afternoon working hours (between 12:30 PM and 5:00 PM). The second break schedule comprises the same total break time as the first, but doubles the frequency of the morning and afternoon breaks with two 10-minute breaks, and offers a shorter 20 -minute lunch break. Finally, the third break schedule provides a larger ( 90 -minute) total break than both previous schedules with two 15-minute break times for both the morning and afternoon working hours. Figure 4 represents results of the second and third break schedules.

Table 3 summarizes the results from applying three different rest break schedules at the panelized modular construction factory. The area between the accumulated recovery time line and the minimum required recovery time is estimated.

Table 3. Alternative break schedule analysis results

\begin{tabular}{lccc}
\hline & $\begin{array}{c}\text { Breaks } \\
(\text { minutes })\end{array}$ & $\begin{array}{c}\text { Area } \\
\left(\mathrm{min}^{2}\right)\end{array}$ & $\begin{array}{c}\text { Reduction } \\
(\%)\end{array}$ \\
\hline Original Schedule & $\begin{array}{l}1 \times 30 \text { minutes } \\
2 \times 15 \text { minutes }\end{array}$ & 8,278 & - \\
Scenario \#2 & $\begin{array}{l}\text { 1 } 20 \text { minutes } \\
4 \times 10 \text { minutes }\end{array}$ & 2,609 & $68 \%$ \\
Scenario \#3 & $1 \times 30$ minutes & 1,032 & $87 \%$ \\
& $4 \times 15$ minutes & & \\
\hline
\end{tabular}

The second rest break scenario, which comprises four 10-minute rest breaks throughout the working hours with a 20 -minute lunch break, shows a $68 \%$ reduction in the total fatigue area compared to the original schedule. With the same total amount of break time (e.g., 60 minutes) as in the original schedule, the second schedule is able to reduce the area without increasing total break time.

Scenario \#2

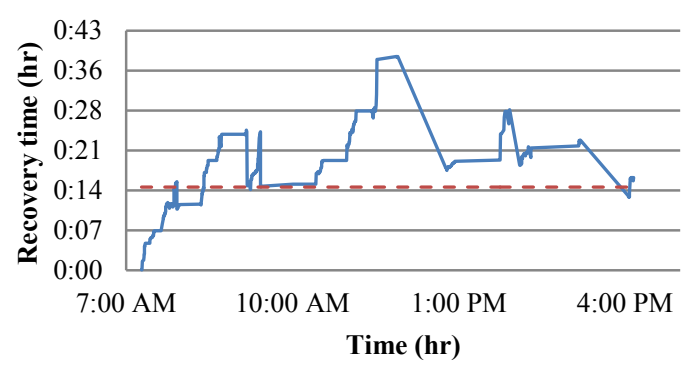

Scenario \#3

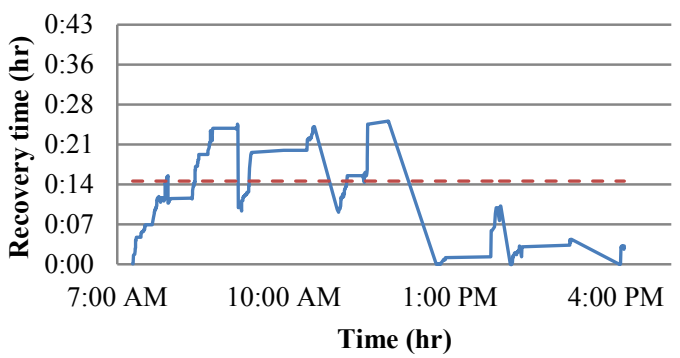

Figure 4. Alternative break schedule recovery time analysis 
The third rest break scenario shows a greater reduction of the area as total break time increases to 90 minutes from 60 minutes. Greater improvement is achieved and $87 \%$ of reduction in the area is achieved. There is no recovery time in afternoon working hours.

Despite the fact that the application of recovery time analysis provides a general overview of fatigue accumulation on back muscles of workers, there are some limitations that can be improved for a future study. The central limitation of this research is the indirect measurement of fatigue using the mathematical model. Direct measurement, such as electromyography (EMG), may provide a more accurate fatigue level of muscles.

\section{CONCLUSION}

This paper examines the relationship between break time schedule and cumulated muscle fatigue. Muscle fatigue is estimated using a mathematical model based on MVC of worker, weight of object, and CT. A case study in a panelized construction factory was performed to discover the effectiveness of break time schedules. Different break time schedules were tested and compared with the actual schedule. The result from case study shows that workers are possibly exposed to potential risk of WMSDs at the panelized construction factory. This would imply a need for longer or more frequent rest break schedules in order to reduce these risks. In the future, this study can be used to evaluate the effectiveness of break time schedules in work places throughout the industry.

\section{ACKNOWLEDGEMENTS}

The authors are grateful for the support from the Natural Sciences and Engineering Research Council of Canada (NSERC) and Landmark Group of Builders in Edmonton, Alberta, Canada.

\section{REFERENCE}

Arlinghaus, A., Lombardi, D., Courtney, T. K., Christiani, D. C., Folkard, S., \& Perry, M. J. (2012). "The effect of rest breaks on time to injury — a study on work-related ladder-fall injuries in the United States." Scandinavian Journal of Work, Environment \& Health, Vol. 38, No. 6 pp. 560-567.

Buckley, B., \& Ichniowski, T. (2010). "Fatalities down, but rate stays flat." ENR, 265 (6):13.

CCOHS. (2016, July 05). Back Injury Prevention. Retrieved from Canadian Centre for occupational health and safety: https://www.ccohs.ca/oshanswers/ergonomics/inj_prev.html

Chaffin, D. B., \& Park, K. S. (1973). "A longitudinal study of low-back pain as associated with occupational weight lifting factors." The American Industrial Hygiene Association Journal, 34.12:513-525.

CPWR. (2004). Hazard Alert - Back Injuries. Retrieved from Electronic Library of Construction Occupational Safety Health: http://www.elcosh.org/document/1196/d000369/Hazard\%2BAlert\%2B-

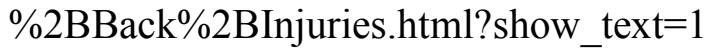

CPWR. (2013). The construction chart book. Silver Spring: Center for construction research and training (CPWR).

Dode, P., Greig, M., Zolfaghari, S., \& Neumann, P. (2016). "Integrating juman factors into discrete event simulation: a proactive approach to simultaneously design for system performance and employees' well being." International Journal of Production Research, $54: 10,3105-3117$. 
El ahrache, K., \& Imbeau, D. (2009). "Comparison of rest allowance models for static muscular work." International Journal of Industrial Ergonomics, (39): 73-80.

Frey-Law, L. A., Looft, J. M., \& Heitsman, J. (2012). "A three-compartment muscle fatigue model accurately predicts joint-specific maximum endurance times for sustained isometric tasks." Journal of biomechanics, 45.10: 1803-1808.

Galinsky, T. L., Swanson, N. G., Sauter, S. L., Hurrell, J. J., \& Schleifer, L. M. (2000). "A field study of supplementary rest breaks for data-entry operators." Ergonomics, 43(5) 622-638.

Golabchi, A., Han, S., Seo, J., Lee, S., \& Al-Hussein, M. (2015). "An Automated Biomechanical Simulation Approach to Ergonomic Job Analysis for Workplace Design." Journal of Construction Engineering and Management, 10.1061/(ASCE)CO.1943-7862.0000998, 04015020.

Government of Alberta. (2011, March 21). Hours of Work, Rest Periods and Days of Rest. Retrieved from Employment Standard: https://work.alberta.ca/employmentstandards/hours-of-work-rest-periods-and-days-of-rest.html

Kamali, M., \& Hewage, K. (2016). Life cycle performance of modular building: A critical review. Renewable and sustainable energy reviews, (62)1171-1183.

Kim, S., Nussbaum, M. A., \& Jia, B. (2011). "Low back injury risks during construction with prefabricated (panelised) walls: effects of task and design factors." Ergonomics, 54.1:6071.

Kumar, S. (2001). "Theories of musculoskeletal injury causation." Ergonomics, 44(1) 17-47.

Lawson, R., Ogden, R., \& Bergin, R. (2012). "Application of modular construction in high-rise building." Journal of architecture engineering, 18(2): 148-54.

Loof, J. M. (2012). Modeling and validating joint based muscle fatigue due to isometric static and intermittent tasks. University of Iowa.

Marras, W. S. (2000). "Occupational low back disorder causation and control." Ergonomics, 43.7:880-902.

McGill, S. M. (1997). "The biomechanics of low back injury: implications on current practice in industry and the clinic." Journal of biomechanics, 30(5) 465-475.

Nussbaum, M. A., Shewchuk, J. P., Kim, S., Seol, H., \& Guo, C. (2009). "Development of a decision support system for residential construction using panellised walls: Approach and preliminary results." Ergonomics, 52.1: 87-103.

Parker, K. G. (2009). Cumulative Trauma Disorders: Current Issues and Ergonomic Solutions. CRC Press .

Perez, J., de Looze, M. P., Bosch, T., \& Neumann, W. P. (2014). "Discrete Event Simulation as an Ergonomic Tool to Predict Workload Exposures during system design." International Journal of Industrial Ergonomics, 44(2):298-306.

Poulsen, E., \& Jorgensen, K. (1971). "Back muscle strength, lifting, and stooped working postures." Applied Ergonomics, 2.3;133-137.

Rohmert, W. (1960). "Determination of the recovery pause for static work of man." Internationale Zeitschrift Für Angewandte Physiologie, 18: 123 